NBER WORKING PAPER SERIES

\title{
SURPRISING COMPARATIVE PROPERTIES OF MONETARY MODELS: RESULTS FROM A NEW DATA BASE
}

\author{
John B. Taylor \\ Volker Wieland \\ Working Paper 14849 \\ http://www.nber.org/papers/w14849
NATIONAL BUREAU OF ECONOMIC RESEARCH
1050 Massachusetts Avenue
Cambridge, MA 02138
April 2009

We are grateful for excellent research assistance by Tobias Cwik and Maik Wolters from Goethe University Frankfurt. Helpful comments by Frank Smets and session participants at the AEA meetings in San Francisco, January 2009, and the German Economic Association monetary committee meeting in Frankfurt are gratefully acknowledged. The views expressed herein are those of the author(s) and do not necessarily reflect the views of the National Bureau of Economic Research.

NBER working papers are circulated for discussion and comment purposes. They have not been peerreviewed or been subject to the review by the NBER Board of Directors that accompanies official NBER publications.

(C) 2009 by John B. Taylor and Volker Wieland. All rights reserved. Short sections of text, not to exceed two paragraphs, may be quoted without explicit permission provided that full credit, including $\odot$ notice, is given to the source. 
Surprising Comparative Properties of Monetary Models: Results from a New Data Base

John B. Taylor and Volker Wieland

NBER Working Paper No. 14849

April 2009

JEL No. C52,E30,E52

\begin{abstract}
$\underline{\text { ABSTRACT }}$
In this paper we investigate the comparative properties of empirically-estimated monetary models of the U.S. economy. We make use of a new data base of models designed for such investigations. We focus on three representative models: the Christiano, Eichenbaum, Evans (2005) model, the Smets and Wouters (2007) model, and the Taylor (1993a) model. Although the three models differ in terms of structure, estimation method, sample period, and data vintage, we find surprisingly similar economic impacts of unanticipated changes in the federal funds rate. However, the optimal monetary policy responses to other sources of economic fluctuations are widely different in the different models. We show that simple optimal policy rules that respond to the growth rate of output and smooth the interest rate are not robust. In contrast, policy rules with no interest rate smoothing and no response to the growth rate, as distinct from the level, of output are more robust. Robustness can be improved further by optimizing rules with respect to the average loss across the three models.
\end{abstract}

John B. Taylor

Herbert Hoover Memorial Building

Stanford University

Stanford, CA 94305-6010

and NBER

John.Taylor@stanford.edu

Volker Wieland

Goethe University Frankfurt

House of Finance, PF H 31

D-60323 Frankfurt/Main

wieland@wiwi.uni-frankfurt.de 
Ever since the 1970s revolution in macroeconomics, monetary economists have been building quantitative models that incorporate the fundamental ideas of the Lucas critique, time inconsistency, and forward-looking expectations, in order to evaluate monetary policy more effectively. The common characteristic of these monetary models, compared with earlier models, is the combination of rational expectations, staggered price and wage setting, and policy rules, all of which have proved essential to policy evaluation.

Over the years the number of monetary models with these characteristics has grown rapidly as the ideas have been applied in more countries, as researchers have endeavoured to improve on existing models by building new ones, and as more data shed light on the monetary transmission process. The last decade, in particular, has witnessed a surge of macroeconomic model building as researchers have further developed the microeconomic foundations of monetary models and applied new estimation methods. In our view it is important for research progress to document and compare these models and assess the value of model improvements in terms of the objectives of monetary policy evaluation. Keeping track of the different models is also important for monetary policy in practice because by checking the robustness of policy in different models one can better assess policy.

With these model comparison and robustness goals in mind we have recently created a new "monetary model base," an interactive collection of models that can be simulated, optimized, and compared. The monetary model base can be used for model comparison projects and policy robustness exercises. Perhaps because of the large number of models and the time and cost of bringing modellers together, there have not been many model comparison projects and robustness exercises in recent years. In fact the most recent policy robustness exercise, which we both participated in, occurred 10 years ago as part of an NBER 
conference. ${ }^{1}$ Our monetary model base provides a new platform that makes model comparison much easier than in the past and allows individual researchers easy access to a wide variety of macroeconomic models and a standard set of relevant benchmarks. ${ }^{2}$ We hope in particular that many central banks will participate and benefit from this effort as a means of getting feedback on model development efforts.

This paper investigates the implications of three well-known models included in the model base for monetary policy in the U.S. economy. The first model, which is a multicountry model of the G-7 economies built more than fifteen years ago, has been used extensively in the earlier model comparison projects. It is described in detail in Taylor (1993a). The other two models are the best known representatives of the most recent generation of empirically estimated new Keynesian models, the Christiano, Eichenbaum and Evans (2005) model of the United States and the Smets and Wouters (2007) model of the United States.

The latter two models incorporate the most recent methodological advances in terms of modelling the implications of optimizing behavior of households and firms. They also utilize new estimation methods. The Christiano, Eichenbaum and Evans (2005) model is estimated to fit the dynamic responses of key macroeconomic variables to a monetary policy shock identified with a structural vector autoregression. The Smets and Wouters (2007) model is estimated with Bayesian methods to fit the dynamic properties of a range of key variables in response to a full set of shocks.

First, we examine and compare the monetary transmission process in each model by studying the impact of monetary policy shocks in each model. Second, we calculate and

\footnotetext{
${ }^{1}$ The results are reported in the conference volume, Monetary Policy Rules, Taylor (1999). Several of the models in this earlier comparison and robustness exercise are also included in our new monetary model base, including Rotemberg-Woodford (1999), McCallum and Nelson (1999), and Taylor (1993).

${ }^{2}$ See the Appendix of this paper for the current list of models and Wieland, Cwik, Müller, Schmidt and Wolters (2009) for a detailed exposition of the platform for model comparison. This platform relies on the DYNARE software for model solution and may be used with Matlab. For further information on DYNARE see Collard and Juillard (2001) and Juillard (1996) and http://www.cepremap.cnrs.fr/dynare/.
} 
compare the optimal monetary policy rules within a certain simple class for each of the models. Third, we evaluate the robustness of these policy rules by examining their effects in each of the other models relative to the rule that would be optimal for the respective model.

The model comparison and robustness analysis reveals some surprising results. Even though the two more recent models differ from the Taylor (1993a) model in terms of economic structure, estimation method, data sample and data vintage, they imply almost identical estimates of the response of U.S. GDP to an unexpected change in the federal funds rate, that is, to a monetary policy shock. This result is particular surprising in light of earlier findings by Levin, Wieland and Williams $(1999,2003)$ indicating that a number of models built after Taylor (1993a) exhibit quite different estimates of the impact of a monetary policy shock and the monetary transmission mechanism. ${ }^{3}$ We also compare the dynamic responses to other shocks. Interestingly, the impact of the main financial shock, that is the risk premium shock, on U.S. GDP is also quite similar in the Smets and Wouters (2008) and the Taylor (1993) model. This finding is of interest in light of the dramatic increase in risk premia observed since the start of the financial crisis in August 2007. ${ }^{4}$ Differences emerge with regard to the consequences of other demand and supply shocks.

The analysis of optimized simple interest rate rules reveals further interesting similarities and differences across the three models. All three models prefer rules that include the lagged interest rate in addition to inflation deviations from target and output deviations from potential. The two more recent new Keynesian models favour the inclusion of the growth rate of output rather than simply the current output gap. The robustness exercise, however, delivers a more pessimistic conclusion. Only the rules that respond to inflation and

\footnotetext{
${ }^{3}$ For example, the model of Fuhrer and Moore (2000) and the Federal Reserve's FRB/US model of Reifschneider, Tetlow and Williams (1999), both exhibited longer-lasting effects of policy shocks on U.S. GDP that peak several quarters later than in Taylor (1993a). See Levin, Wieland and Williams $(1999,2003)$ for a comparison.

${ }^{4}$ As noted by Smets and Wouters (2007) the risk premium shock represents a wedge between the interest rate controlled by the central bank and the return on assets held by the households and has similar effects as so-called net-worth shocks in models with an explicit financial sector such as Bernanke et al (1999).
} 
the output gap exhibit reasonably robust performance across models, when a rule optimized in one model is applied in another one. Rules that also include the lagged interest rate, or the lagged output gap, are not robust. Robustness can be improved a lot by optimizing the policy rule with respect to the average loss across the models.

\section{Brief Description of the Models}

\section{Taylor (1993a)}

This is an econometrically-estimated rational expectations model fit to data from the G7 economies for the period 1971:1 to 1986:4. All our simulations focus on the United States. The model was built to evaluate monetary policy rules and was used in the original design of the Taylor rule. It has also been part of several model comparison exercises including Bryant et al (1985), Klein (1991), Bryant et al (1993) and Taylor (1999). Shiller (1991) compared this model to the "old Keynesian" models of the pre rational expectations era, and he found that there were large differences in the impact of monetary policy due largely to the assumptions of rational expectations and more structural models of wage and price stickiness.

To model wage and price stickiness Taylor (1993a) used the staggered wage and price setting approach rather than ad hoc lags of prices or wages which characterized the older prerational expectations models. However, because the Taylor (1993a) model was empirically estimated it used neither the simple example of constant-length four-quarter presented in Taylor (1980) nor the geometrically-distributed contract weights proposed by Calvo (1983). Rather it lets the weights have a general distribution which is empirically estimated using aggregate wage data in the different countries. In Japan some synchronization is allowed for.

The financial sector is based on several "no-arbitrage" conditions for the term structure of interest rates and the exchange rate. Expectations of future interest rates affect consumption and investment, and exchange rates affect net exports. Slow adjustment of consumption and investment is explained by adjustment costs such as habit formation or 
accelerator dynamics. A core principle of this model is that after a monetary shock the economy returns to a growth trend described by a model with flexible prices. The growth trend is assumed to be exogenous to monetary policy as in the classical dichotomy.

Most of the equations of the model were estimated with Hansen's instrumental variables estimation method, with the exception of the staggered wage setting equations which were estimated with maximum likelihood.

\section{Christiano, Eichenbaum, Evans (2005)}

Many of the equations in the model of Christian, Eichenbaum and Evans (CEE 2005 in the following) exhibit similarities to the equations in the Taylor model, but they are explicitly-derived log-linear approximations of the first-order conditions of optimizing representative firms and households. Their model also assumes staggered contracts but with Calvo weights and backward-looking indexation in those periods when prices and wages are not set optimally. Long-run growth and short-run fluctuations are modelled jointly rather than separately as in Taylor's model. Thus, the CEE (2005) model explicitly accounts for labor supply dynamics as well as the interaction of investment demand, capital accumulation and utilization. Furthermore, their model includes a cost-channel of monetary policy. Firms must borrow working capital to finance their wage bill. Thus, monetary policy rates have an immediate impact on firms’ profitability.

The CEE (2005) model was estimated for the U.S. economy over the period 1959:22001:4 by matching the impulse response function to the monetary shock in a structural VAR. An important assumption of the VAR that carries over to the model is that monetary policy innovations affect the interest rate in the same quarter, but other variables, including output and inflation, only by the following quarter.

The monetary policy innovation represents the single, exogenous economic shock in the original CEE model. However, additional shocks can be incorporated in the structural 
model and the variance of such shocks may be estimated using the same methodology. The additional shocks would first be identified in the structural VAR. Then, the parameters of the structural model including innovation variances would be re-estimated by matching the impulse response functions implied by the model with their empirical counterparts from the VAR. Altig, Christiano, Eichenbaum and Linde (2004), (ACEL 2004 in the following), follow this approach and identify two additional shocks - a neutral and an investment-specific technology shock. These shocks exhibit serial correlation and have permanent effects on the level of productivity. Together with the monetary policy shock they account for about $50 \%$ of the variation in output. The impulse response function for the monetary policy shock in ACEL (2004) is almost identical to CEE (2005). Therefore, we will use the ACEL (2004) parameterization of the CEE model for the computational analysis in our paper. A drawback of this model is that it does not yet provide a complete characterization of the observed output and inflation volatility.

The CEE model, which was initially circulated in 2001, represented the first mediumsized, estimated example of the new generation of New-Keynesian dynamic stochastic general equilibrium models explicitly derived from optimizing behavior of representative households and firms. ${ }^{5}$ It stimulated the development of similar optimization-based models for many other countries once Smets and Wouters (2003) showed how to make use of new advances in Bayesian techniques (see e.g. Geweke (1999) and Schorfheide (2000)) in estimating such models.

\section{Smets and Wouters (2007)}

The model of the U.S. economy estimated by Smets and Wouters (2007) (SW 2007 in the following) with U.S. data from 1966:1 to $2004: 4$ may be viewed as an extended version of the CEE/ACEL model. The SW model contains a greater set of macroeconomic shocks and aims

\footnotetext{
${ }^{5}$ The paper was published in 2001 as NBER Working Paper 8403.
} 
to fully explain the variation in key variables, such as aggregate output and its components as well as inflation, wages and interest rates. They use a Bayesian estimation methodology that allows the use of priors on model parameters informed from theory and literature. The posterior distributions then incorporate the information in the available macroeconomic data. Whenever the data does not help in pinpointing parameter values very precisely, theoretical priors dominate. Such priors can in some cases be based on evidence from microeconomic studies. The Bayesian estimation methodology has quickly been popularized and widely applied by researchers in central banks and academia. It has been implemented for use with the DYNARE software that we also utilize in our model base.

Smets and Wouters (2007) modify some of the structural assumptions embodied in the CEE/ACEL model. In the long-run, the SW model is consistent with a balanced steady-state growth path driven by deterministic labor-augmenting technological progress. While the CEE model assumes wages and prices are indexed to last period's inflation rate in the absence of a Calvo-style signal, the SW model allows firms to index to a weighted average of lagged and steady-state inflation. Furthermore, SW drop two more assumptions that have important shortrun implications in the CEE/ACEL model. First, they do not impose the delayed effect of monetary policy on other variables that CEE built into the structural model so as to match the constraints required by the structural VAR to identify monetary policy shock. Second, SW (2007) do not require firms to borrow working capital to pay the wage bill. Thus, the so-called cost channel is absent from the model. Smets and Wouters note that they did not find this channel necessary for fitting the dynamics in U.S. data. In our simulations, we will also investigate the implications of adopting the SW assumptions of no cost channel and no timing constraints on monetary policy shocks in the original CEE/ACEL model. 


\section{Shocks to Monetary Policy as Deviations from Two Policy Rules}

We first use model base to assess the extent of differences between models regarding the transmission of monetary policy to output and inflation. To this end we compare the effect of monetary policy shocks in the three models. A monetary policy shock is defined as a surprise deviation from systematic policy behavior which is characterized by interest rate policy rules.

In our comparison, we focus on two estimated rules used by SW 2007 and CEE 2005 respectively to characterize systematic central bank policy. Smets and Wouters estimate the coefficients of this interest rate rule along with the other equations in their model. We refer to it as the SW rule in the remainder of the paper. They call it a generalized Taylor rule, because it includes the lagged federal funds rate and the growth rate of output, in addition to the inflation rate and the output gap that appear in the Taylor (1993b) rule. It implies the following setting for the federal funds rate, $\mathrm{i}_{\mathrm{t}}$ :

$$
i_{t}=0.81 i_{t-1}+0.39 \pi_{t}+0.97 y_{t}-0.90 y_{t-1}+\varepsilon_{t}^{i}
$$

Here, $\pi_{\mathrm{t}}$ refers to the annualized, quarterly inflation rate and $y_{t}$ to the output gap. ${ }^{6}$ In the Taylor model (and the original Taylor rule) the output gap is defined as difference between actual output and long-run potential output. ${ }^{7}$ In the SW and CEE model the gap measure used in the policy rule is defined as the difference between the actual output level and the level that would be realized if prices adjust flexibly to macroeconomic shocks, the so-called flex-price output level. The policy shock is denoted by $\varepsilon_{\mathrm{t}}^{\mathrm{i}}$. Due to the inclusion of the lagged interest rate in the reaction function, such a one-time shock will have a persistent effect on nominal

\footnotetext{
${ }^{6}$ Note, the response coefficients differ from the values reported in SW 2007. In equation (1), interest and inflation rates are annualized, while SW used quarterly rates. The original specification in SW 2007 corresponds to $i_{t}^{q}=(1-0.81)\left(2.04 \pi_{t}^{q}+0.09 y_{t}\right)+0.22 \Delta y_{t}+0.81 i_{t-1}^{q}+\varepsilon_{t}^{i}$, where the subscript $q$ refers to quarterly rates.

${ }^{7}$ Smets and Wouters set wage and price markup shocks equal to zero in the derivation of the flex-price output measure used to define the output gap.
} 
interest rates and due to price rigidity also on real rates and aggregate output. Under the original Taylor (1993b) rule a one-time shock $\varepsilon_{t}^{i}$ influences the nominal interest rate only for one period.

CEE (2005) define the central bank's policy rule in terms of a reaction function for the growth rate of money. ${ }^{8}$ They identify monetary policy shocks in a structural VAR as orthogonal innovations to the interest rate reaction function. Then, they estimate the parameters of the structural model including the parameters of the money growth rule by matching the impulse response in the structural model and the VAR. In addition, they contrast their findings under the money growth rule with the effect of a policy shock under an extended Taylor rule for the federal funds rate: ${ }^{9}$

$$
i_{t}=0.80 i_{t-1}+0.3 E_{t} \pi_{t+1}+0.08 y_{t}+\varepsilon_{t}^{i}
$$

Just like the SW rule it incorporates partial adjustment to the lagged federal funds rate.

However, it is forward-looking and responds to the expected inflation rate for the upcoming quarter. The coefficient on the output gap is much smaller than in the SW rule and it does not include the lag of the output gap. In the following we refer to this rule as the CEE rule.

\section{Monetary Policy Shocks in Three Monetary Models of the U.S. Economy}

We compare the consequences of a monetary policy shock in the Taylor, SW and CEE/ACEL models to shed light on their implications for the transmission of Federal Reserve interest rate decisions to aggregate output and inflation. In particular, we want to find out to what extent the current-generation DSGE models, CEE/ACEL (2004) and SW (2007), imply quantitatively different effects of monetary policy than the model by Taylor (1993a). Since

\footnotetext{
${ }^{8} \mathrm{CEE}$ (2005) and ACEL(2004) model monetary policy in terms of innovations to the growth-rate of money that they denote by $\mu_{t}: \mu_{t}=\mu+\theta_{0} \varepsilon_{t}+\theta_{1} \varepsilon_{t-1}+\theta_{2} \varepsilon_{t-2}+\theta_{3} \varepsilon_{t-3} \cdots$

${ }^{9}$ Note, we use annualized interest and inflation rates and transcribe the CEE rule accordingly. In CEE 2005 they define their rule as: $i_{t}^{q}=(1-0.80)\left(1.5 E_{t} \pi_{t+1}^{q}+0.1 y_{t}\right)+0.8 i_{t-1}^{q}+\varepsilon_{t}^{i}$. CEE (2005) attribute this estimated rule to Clarida et al (1999). However, the coefficients reported in Clarida et al (1999) are different. Their rule corresponds to $i_{t}=(1-0.79)\left(2.15 E_{t} \pi_{t+1}+0.93 y_{t}\right)+0.79 i_{t-1}+\varepsilon_{t}^{i}$.
} 
the models differ in terms of economic structure and parameter estimates are obtained for different data series, estimation periods and data vintages, we would expect to obtain quantitatively different assessments of the monetary transmission mechanism.

Figure 1 reports the consequences of a 1 percentage point shock to the federal funds rate for nominal interest rates, output and inflation. The panels on the left-hand side refer to the outcomes when the Federal Reserve sets interest rates following the initial shock according to the prescriptions of the SW rule, while the right-hand-side panels refer to the outcome under the CEE rule. Each panel shows the findings from four model simulations. The dark solid line refers to the Taylor model, the light solid line to the SW model, the dashed line to the CEE/ACEL model and the dotted line to the CEE/ACEL model with SW assumptions. ${ }^{10}$

Surprisingly, the effect of the policy shock on real output and inflation given a common policy rule is very similar in the four models. For example, under the SW rule the nominal interest rate increases on impact by 0.8 to 1 percentage points and then returns slowly to stead state, real output falls over three to four quarters to a trough of about -0.28 percent before returning to steady-state, and inflation declines more slowly with a trough of 15 basis points about 2 quarters later than output.

The quantitative implications for real output in the Taylor (1993) and SW (2007) models are almost identical. The outcome under the CEE/ACEL model initially differs slightly from the other two models. In the quarter of the shock we observe a tiny increase in output, while inflation does not react at all. From the second quarter onwards output declines to the same extent as in the other two models but the profile is shifted roughly one quarter into the future. The decline in inflation is similarly delayed. Once we implement the CEE/ACEL model with

\footnotetext{
${ }^{10}$ The CEE/ACEL model with SW Assumptions implies the following modifications: We remove the timing constraints that were imposed on the structural model by the authors so that it coincides with the identification restrictions on the VAR that they used to obtain impulse responses for the monetary policy shock. Furthermore we remove the constraint from the ACEL model that requires firms to finance the wage bill by borrowing cash in advance from a financial intermediary. As a result of this constraint the interest rate has a direct effect on firms' costs.
} 
the SW assumptions of no timing constraint on policy and no cost channel, the output and inflation dynamics are more similar to the other two models.

The original Lucas critique stated that a change in the systematic component of policy would have important implications for the dynamics of macroeconomic variables. This effect becomes apparent when we switch from the SW rule to the CEE rule. Under the CEE rule the policy shock has a greater effect on output which reaches a trough between -0.32 and -0.37 percent. Again, however, the magnitude of the effect of the policy shock on real output and inflation is almost identical in the Taylor model, the SW model and the ACEL/CEE model, particularly when the latter model is implemented with the SW assumptions.

Furthermore, we have computed the real output effects of a monetary policy shock with different response coefficients (for example, a four times smaller response to output), different inflation measures (such as year-on-year inflation) and different rules such as the original Taylor rule or the benchmark rules considered in Levin, Wieland and Williams (2003) and Kuester and Wieland (2008). Different rules have quite different implications for the real consequences of monetary policy shocks. However, the Taylor model, the SW model and the CEE model continue to imply surprisingly similar dynamics of aggregate real output and inflation in response to policy shock for a given, common policy rule.

The finding that the two best-known models of the recent generation of new Keynesian models provide very similar estimates of the impact of a policy shock on U.S. real GDP as the model of Taylor (1993a) is particularly surprising in light of earlier comparison projects. For example, the comparison in Levin, Wieland and Williams (1999) and (2003) indicated that models built and estimated after Taylor (1993a) such as the model of Fuhrer and Moore (1995) or the Federal Reserve's FRB/US model of Reifschneider, Tetlow and Williams (1999) provided different assessments of the U.S. monetary transmission mechanism. In particular, these models suggested that the impact of monetary policy shocks on real output 
would be longer-lasting and reach its peak more than a year after the initial impulse. This view is often considered conventional wisdom among practitioners.

So far we have focused on the overall effect of the policy shock on output and inflation. Now we turn to the effects on other macroeconomic variables. Figure 2 illustrates some additional common aspects of the transmission mechanism in the three models of the U.S. economy, while Figure 3 highlights interesting differences. Monetary policy is assumed to follow the SW rule after the policy shock. ${ }^{11}$ The real interest rate increases almost to the same extent in all three models as shown in panel 2a. As a result, aggregate consumption and aggregate investment decline. The decline in consumption is smaller in the Taylor model than in the other two models, while the decline in investment is much greater. Also, real wages decline along with aggregate demand in all three models.

The three models also exhibit some interesting differences regarding the transmission of monetary policy shocks. For example, panels a. and b. in Figure 3 indicate that only the Taylor model accounts for international feedback effects. As a result of the policy shock the US dollar appreciates temporarily in real trade-weighted terms. Exports and imports, both, decline. However, the fall in imports is much greater than in exports and as a result net exports increase. The strong decline in imports occurs due to the domestic demand effect that figures very importantly in the U.S. import demand equation. The resulting increase in net exports partly offsets the impact of the large negative decline in investment demand on aggregate output in the Taylor model. Furthermore, panels c. through f. in Figure 3 illustrate that only the SW and CEE models account for the effects of the policy shock on labor supply, capital stock, the rental rate of capital and capital utilization. All four measures decline in response to the monetary shock. This explanation of supply-side dynamics is missing from the Taylor model.

\footnotetext{
${ }^{11}$ Similar figures for the case of the CEE rule are provided in the appendix.
} 


\section{Other shocks and their implications for policy design}

Unexpected changes in monetary policy are of interest in order to identify aspects of the monetary transmission mechanism. When it comes to the question of policy design, however, the standard recommendation is to avoid policy surprises since they only generate additional output and inflation volatility. Instead optimal and robust policy design focuses on the proper choice of the variables and the magnitude of the response coefficients in the policy rule that characterizes the systematic component of monetary policy. The policy rule is then designed to stabilize output and inflation in the event of shocks emanating from other sectors of the economy. In this respect, it is of interest to review and compare the potential sources of economic shocks in the three models under consideration.

In light of the recent financial crisis, we start by comparing the effect of particular financial shocks. Only the Taylor and SW models contain such shocks. Figure 4 illustrates the effect of an increase in the term premium by 1 percentage point on real output and inflation in the Taylor and SW models. The initial impact of these shocks on real output is almost identical in the two models and lies between -0.22 and -0.24 percent of output. This finding is particularly surprising since the shocks are estimated quite differently in the two models. In the Taylor model the term premium shock is estimated from the term structure equation directly using data on short- and long-term interest rates, that is, the federal funds rate versus 10-year US treasuries. In the SW model the risk premium shock is estimated from the consumption and investment equation. It assumes the term structure relation implicitly but uses no data on long-term rates. In earlier work on the euro area, Smets and Wouters (2003) included instead a consumption demand or preference shock. This shock is omitted in their model of the U.S. economy to keep the number of shocks in line with the number of observed variables. SW emphasize that the premium shock represents a wedge between the interest rate controlled by the central bank and the return on assets held by the households and has similar 
effects as so-called net-worth shocks in models with an explicit financial sector such as Bernanke et al (1999). ${ }^{12}$

Figure 5 provides a comparison of what could be termed "demand" or "spending" shocks in the three models. These are shocks that push output and inflation in the same direction. The Taylor model contains many such shocks. Panels a. and b. show the effects of shocks to nondurables consumption, equipment investment, inventory investment, government spending and import demand on the output gap and inflation. The SW model contains two shocks of this type, an exogenous spending shock that comprises government spending as well as net exports and an investment-specific technology shock. The ACEL model contains an investment-specific technology shock that initially lowers inflation but then raises it. It has stronger long-term effects than the investment-specific technology shock in SW (2007).

Figure 6 compares supply shocks in the three models, i.e. shocks that push output and inflation in opposite directions. The Taylor model has a number of such shocks, in particular innovations to the contract wage equations, the final goods price equation, import prices and export prices. The SW model contains price mark-up and wage markup shocks that are somewhat similar to the contract wage and aggregate price shocks in the Taylor model. Only the SW and the ACEL models include neutral technology shocks. In the ACEL model these shocks have a long-term effect on productivity growth, while their effect on productivity growth in the SW model is temporary.

Comparing the three models, it is important to keep in mind that only the Taylor and SW model aim to fully explain the variation in the macroeconomic variables included in the model as an outcome of exogenous shocks and endogenous propagation. The ACEL model

\footnotetext{
${ }^{12}$ In the model file available from the AER website along with the SW (2007) paper the shock is multiplied with minus the consumption elasticity. This is consistent with figure 2 of that paper, where the shock appears as a "demand" shock, i.e. an increase has a positive effect on output. It is not consistent with equation (2) in SW (2007) that identifies the shock as a risk premium shock (i.e. an increase has a negative effect). We have modified the model file consistent with the notation as risk premium shock in equation (2) in SW (2007). In addition, we have checked that re-estimating the SW model with the shock entering the consumption Euler equation as defined by equation (2) in their paper does not have an important effect on the parameter estimates.
} 
only aims to explain that part of the variation that is caused by the three shocks in the structural VAR that was used to identify them. Figures 5 and $\mathbf{6}$ indicate that the investmentspecific and neutral technology shocks in the ACEL model have negligible effects on inflation. Consequently, the ACEL model omits most sources of inflation volatility outside of policy shocks and is of limited usefulness for designing monetary policy rules. With this caution in mind, we will nevertheless explore the implications of the ACEL model for policy design together with the other two models.

\section{Optimal simple policy rules in the Taylor, CEE/ACEL and SW models}

The first question on policy design, that we address concerns the models' recommendations for the optimal policy response to a small number of variables in a simple interest rate rule. We start by considering rules that incorporate a policy response to two variables, that is, the current year-on-year inflation rate and the output gap as in the original Taylor (1993b) rule:

$$
i_{t}=\alpha \pi_{t}+\beta_{0} y_{t}
$$

In a second step, we extend the rule to include the lagged nominal interest rate as in Levin, Wieland and Williams $(1999,2003)$ :

$$
i_{t}=\rho i_{t-1}+\alpha \pi_{t}+\beta_{0} y_{t}
$$

Finally, we also include the lagged output gap as in the estimated rule in the Smets and Wouters (2007) model:

$$
i_{t}=\rho i_{t-1}+\alpha \pi_{t}+\beta_{0} y_{t}+\beta_{1} y_{t-1}
$$


We choose the response coefficients of the rules (i.e. $\rho, \alpha, \beta_{0}, \beta_{1}$ ) in each of the models by minimizing a loss function $L$ that includes the unconditional variances of inflation, the output gap and the change of the nominal interest rate:

$$
L=\operatorname{Var}(\pi)+\lambda_{y} \operatorname{Var}(y)+\lambda_{\Delta i} \operatorname{Var}(\Delta i)
$$

A range of alternative weights on output and interest rate volatility is considered: $\lambda_{y}=(0,0.5,1)$ and $\lambda_{\Delta \mathrm{i}}=(0.5,1)$. The output gap $y$ is defined as the deviation of actual output from the level of output that would be realized if the price level were fully flexible. In the Taylor model this level of output grows at an exogenous rate. In the SW and ACEL models, however, flexibleprice output varies in response to some of the economic shocks. We use the same definition of flexible price output as in Smets and Wouters (2007).

The optimized response coefficients are shown in Table 1. It reports results for two-, three- and four-parameter rules in the Taylor, SW and CEE/ACEL models. The central bank's objective is assumed to assign a weight of unity to inflation and interest rate volatility and either a weight of zero or unity to output gap volatility. ${ }^{13}$ First, with regard to twoparameter rules all three models prescribe a large response coefficient on inflation and a small coefficient on the output gap, if the output gap does not appear in the loss function. If the output gap receives equal weight in the loss function then the optimal coefficient on output increases but remains quite a bit below the response to inflation. The coefficient on inflation declines in the SW and CEE/ACEL models but increases in the Taylor model when output appears in the loss function.

\footnotetext{
${ }^{13}$ Additional findings for a weight of 0.5 on the unconditional variance of the change of the nominal interest rate are reported in the appendix. Further sensitivity studies for intermediate weights have been conducted but are not shown.
} 
For three-parameter rules the optimized value of the coefficient on the lagged nominal interest rate is near unity. This property applies in all three models and with different values of the objective function weights except for one case that is discussed below. The coefficients on inflation are much smaller than in the two-parameter rules but they typically remain positive. In the ACEL model the loss function is very flat. There appear to be multiple local optima and the global optimum we identify has very extreme coefficients in the case of the three-parameter rule with a positive weight on output gap volatility in the loss function. ${ }^{14} \mathrm{We}$ attribute this property of the ACEL model to the fact that it only contains two technology shocks that explain little of the variation of inflation and output gaps but have permanent effects on the growth of steady state output. The ACEL model contains no short-run demand and supply shocks as do the other two models. For this reason the model may not be considered suitable in its current form for an evaluation of the role of interest rate rules in stabilization policy. Nevertheless, we continue to replicate the analysis conducted in the other two models also in the ACEL model throughout this paper.

Next, we turn to the rules with four parameters that include the lagged output gap in addition to current output, inflation and the lagged interest rate. The coefficients on the lagged interest rate typically remain near unity. Interestingly, the coefficient on the lagged output gap, that is $\beta_{1}$, in the CEE/ACEL and SW models is almost equal to $-\beta_{0}$, the coefficient on the current output gap. Thus, the CEE/ACEL and SW models appear to desire a policy response to the growth rate of the output gap rather than its level. This is not the case in the Taylor model.

Table 2 reports on the relative stabilization performance with two-, three- and fourparameter rules. Two different measures are reported, the percentage increase in loss and, in parentheses, the absolute increase in loss when one reduces the number of parameters (and therefore variables) in the policy rule starting from the case of four-parameter rules. In the

\footnotetext{
${ }^{14}$ A local optimum at less extreme values is observed for $\rho=0.01, \alpha=2.9, \beta_{0}=0.5$.
} 
following, we will focus on the absolute loss differences because the percentage differences tend to give misleading signals.

The particular measure of the increase in absolute loss that is shown is the implied inflation variability premium proposed by Kuester and Wieland (2008) (referred to as the IIP in the following). This measure translates a particular increase in absolute loss into the increase in the standard deviation of inflation (in percentage point terms) that would raise the loss to the same extent keeping all else equal (i.e. for a constant output or interest volatility). The advantage of this measure is that it is easily interpreted in practical terms and therefore provides a clear signal of those properties of interest rate rules that are of economic importance.

To give an example, consider the number in the first row and fourth column of Table 2 in parentheses. Its value is 2.14 and it implies the following: if the Taylor model represents the U.S. economy and the central bank considers using the optimized two-parameter rule instead of an optimized three-parameter rule, and if the central bank's loss-function assigns equal weight to output and inflation, the resulting increase in loss (due to higher inflation, output and interest volatility) is equivalent to an increase in the standard deviation of inflation of 2.14 percentage points all else equal. This difference is economically important. Although, it is the largest IIP reported in the table the associated percentage increase of $98.8 \%$ is only the fourth-largest in the table. The third-largest percentage increase in the table is $229 \%$. It is associated with a switch from the three-parameter to the two-parameter rule in the ACEL model when the central bank's loss function assigns zero weight to output volatility. However, the associated IIP of 0.04 is tiny. Thus, the particular switch in rule is economically irrelevant in spite of the large percentage increase in loss. In this case, the reason is that the ACEL model only contains two shocks that cause little inflation volatility and very small losses. 
The findings in Table 2 suggest that there is little additional benefit from including the lagged output gap in the rule. Dropping the lagged output gap from the rule barely increases the central bank's loss. The associated IIP's lie between 0.001 and 0.47 . However, it appears very beneficial to include the lagged interest rate in the rule. Dropping the lagged interest rate from the rule and moving from three to two response parameters implies an economically significant increase in the central bank's loss function, in particular in the Taylor and SW models.

\section{Robustness}

What if the model used by the central bank in designing a policy rule is not a good representation of the economy and one of the other two models provides a much better representation of the U.S. economy? In other words, how robust are model-specific optimized policy rules with respect to the range of model uncertainty reflected in the three models considered in this paper? Table 3 provides an answer to these questions. Robustness is measured in the following manner. The rule optimized for model $\mathrm{X}$ is implemented in model Y. The resulting loss in model $\mathrm{Y}$ is compared to the loss that would be realized under the rule with the same number of parameters that has been optimized for that particular model. The difference is expressed in terms of IIP only.

The findings in Table 3 show that from the perspective of a central bank that aims to minimize inflation and interest rate volatility but assigns no weight to output volatility $\left(\lambda_{\mathrm{y}}=0\right)$, all three classes of policy rules are quite robust. Typically, a rule optimized in one of the models performs quite well in any of the other model compared to the best possible rule with the same number of parameters in that model.

Unfortunately, the preceding conclusion is almost completely reversed when one takes the perspective of a policy maker who cares equally about output and inflation volatility, i.e. 
when $\lambda_{y}=1$. In this case, the policy rules with four parameters are not robust. For example, using the four-parameter rule that is optimal in the SW model instead in the Taylor model, implies an IIP of 2.71. Alternatively, the four-parameter rule optimized for the Taylor model implies an IIP of 7.18 in the SW model and generates multiple equilibria in the ACEL model.

As indicated previously in Table 2, setting the policy response to the lagged output gap to zero comes at little cost in terms of increased output, inflation and interest volatility in a given model. Unfortunately, however, the findings in the middle, two columns of Table 3 indicate that rules with three parameters also lack robustness. Only the rules with two parameters that respond to inflation and the current output gap deliver a fairly robust stabilization performance across the three models. The IIP's are always substantially below unity and often near zero.

Table 4 shows that an evaluation of robustness properties delivers the same conclusions if the CEE/ACEL model is dropped from the analysis. A policymaker with a strong preference for robustness against model uncertainty may therefore prefer to choose an optimized two-parameter rule that responds to inflation and the output gap but not the lagged interest rate. Unfortunately, such rules perform quite a bit worse than the three parameter rules that include the lagged interest rate when it is known which of the models best captures the true dynamics in the economy. To quantify this loss, we re-compute the robustness properties of the two-parameter rules in Table 4 with respect to the best four-parameter rule in the respective model. The implied increase in absolute loss as measured by the IIP is shown in parentheses in the first column of Table 4. These IIP's are relatively high but still indicate that the 2-parameter rules remain more robust to model uncertainty than a three- or four parameter rule.

Using the model data base it is possible to optimize a particular policy rule with respect to multiple models by minimizing the average loss across models. This approach has been proposed, for example, by Levin, Wieland and Williams (2003) and Brock, Durlauf and 
West (2003). In this case, the response coefficients of the rules (i.e. $\rho, \alpha, \beta_{0}, \beta_{1}$ ) are chosen to minimize the average loss across the three models:

$$
\sum_{m=1}^{3} \frac{1}{3} L_{m}=\sum_{m=1}^{3} \frac{1}{3}\left(\operatorname{Var}\left(\pi_{m}\right)+\lambda_{y} \operatorname{Var}\left(y_{m}\right)+\lambda_{\Delta i} \operatorname{Var}\left(\Delta i_{m}\right)\right)
$$

Here, the subscript $m$ refers to a particular model. We focus on the performance of such rules in those cases where model-specific rules were not robust such as when the central bank assigns similar weights to output and inflation in the loss functions. The parameter values for the model averaging rules are reported in Table 5. The 2-parameter rules are similar to the model-specific optimization because those were already quite robust. The interest-smoothing coefficient for 3- and 4-parameter rules now lies in between the values that are optimal in the SW and the TAYLOR model, while the response to inflation is increased.

The robustness of the model averaging rules is studied in Table 6 . The findings confirm that the model-specific 2-parameter rules are quite robust. Model averaging, however, helps to identify rules with interest smoothing that are also robust across the three models and regain much of the improvement in stabilization performance that is promised by the model-specific rules with interest rate smoothing.

\section{Conclusions}

The preceding comparison of the Taylor (1993a) model with the two well-known examples from the current generation of new Keynesian models of the U.S. economy by Christiano, Eichenbaum and Evans (2005) and Smets and Wouters (2007) indicates a surprising similarity of the U.S. monetary transmission mechanism. The empirical, model-based assessment of the impact of an unanticipated change in the federal funds rate on real U.S. GDP has not changed in 14 years that lie in between the publication of these models. This finding is encouraging for policy makers that want to rely on such models. It differs from earlier comparison projects 
which showed that models built later in the 1990s such as the FRB/US model suggested that the impact of policy shocks on real output was much more drawn out over time. Conventional wisdom on the lags of monetary policy decisions may therefore need to be revised.

The robustness analysis of simple policy rules with the three models is less encouraging than the comparative assessment of the transmission mechanism. If the central bank has the task of stabilizing both output and inflation, then an optimal rule in one of our models is not robust in the other models. However, by sacrificing optimality in each model one can find a policy rule which is robust across all three models. For example, rules with no interest rate smoothing and no response to the growth rate, as distinct of the level of output, are surprisingly robust. Furthermore, model averaging provides an avenue for improving the robustness of rules with interest rate smoothing. 


\section{References}

Altig, David, Lawrence, Christiano, Martin Eichenbaum, and Jesper Linde. (2004). "FirmSpecific Capital, Nominal Rigidities and the Business Cycle." Working Paper Series, WP-0501, Federal Reserve Bank of Chicago.

Bernanke, Ben, Mark Gertler and Simon Gilchrist, (1999). "The Financial Accelerator in a Quantitative Business Cycles Framework." in John B. Taylor and Michael Woodford, eds., Handbook of Macroeconomics Volume 1C. Amsterdam: Elsevier Science, North-Holland.

Brock, William, Steven Durlauf, and Kenneth West, (2003), "Policy Evaluation in Uncertain Environments", Brookings Papers on Economic Activity, 1:2003, 235-302.

Bryant, Ralph, David Currie, Jacob Frenkel, Paul Masson, and Richard Portes, eds. (1989). Macroeconomic Policies in an Interdependent World. Washington, D.C.: The Brookings Institution.

Bryant, Ralph, Peter Hooper, and Catherine Mann, eds. (1993). Evaluating Policy Regimes: New Research in Empirical Macroeconomics. Washington, D.C.: The Brookings Institution.

Calvo, Guillermo (1983). "Staggered Prices in a Utility-Maximizing Framework." Journal of Monetary Economics 12: 383-98.

Christiano, Lawrence, Martin Eichenbaum, and Charles Evans. (2005). "Nominal Rigidities and the Dynamic Effects of a Shock to Monetary Policy." Journal of Political Economy 113, 1: $1-45$.

Clarida, Richard, Jordi Gali and Mark Gertler (1999). "The Science of Monetary Policy: A New-Keynesian Perspective." Journal of Economic Literature 37 (December): 1661-1707.

Collard, Fabrice and Michael Juillard (2001). "Accuracy of Stochastic Perturbation Methods: The Case of Asset Pricing Models." Journal of Economic Dynamics and Control 25: 979999.

Fuhrer, Jeffrey and George Moore. (1995), "Inflation Persistence." Quarterly Journal of Economics 110, 1: 127-159.

Geweke, John (1999). "Using Simulation Methods for Bayesian Econometric Models: Inference, Development and Communication." Econometric Reviews 18: 1-126.

Juillard, Michel. (1996), "Dynare: A Program for the Resolution and Simulation of Dynamic Models with Forward Variables Through the Use of a Relaxation Algorithm." CEPREMAP working paper, 9602.

Klein, Lawrence, ed. (1991). Comparative Performance of U.S. Econometric Models. Oxford, Eng.: Oxford University Press.

Kuester, Keith, and Volker Wieland (2008). "Insurance Policies for Monetary Policy in the Euro Area." Journal of the European Economic Assocation, forthcoming. 
Levin, Andrew, Volker Wieland, and John. C. Williams. (1999), "Robustness of Simple Monetary Policy Rules under Model Uncertainty," in John B. Taylor, ed., Monetary Policy Rules. Chicago: University of Chicago Press, 1999.

Levin, Andrew, Volker Wieland, and John. C. Williams. (2003). "The Performance of Forecast-Based Monetary Policy Rules under Model Uncertainty." American Economic Review 93, 3: 622-645.

Lucas, Robert (1976). "Econometric Policy Evaluation: A Critique." Carnegie-Rochester Conference Series on Public Policy 1: 19-46.

McCallum, Bennett, and Edward Nelson. (1999), "Performance of Operational Policy Rules in an Estimated Semi-Classical Structural Model," in John B. Taylor, ed., Monetary Policy Rules. Chicago: University of Chicago Press, 1999.

Reifschneider, David, Tetlow, Robert and John C. Williams. (1999), "Aggregate Disturbances, Monetary Policy, and the Macroeconomy: The FRB/US Perspective." Federal Reserve Bulletin, 85, 1: 1-19.

Rotemberg, Julio and Michael Woodford. (1999), "Interest-Rate Rules in an Estimated Sticky Price Model," in John B. Taylor, ed., Monetary Policy Rules. Chicago: University of Chicago Press, 1999.

Schorfheide, Frank (2000). "Loss Function Based Evaluation of DSGE Models." Journal of Applied Econometrics 15, 6: 645-670.

Smets, Frank and Raf Wouters. (2003), "An Estimated Dynamic Stochastic General Equilibrium Model of the Euro Area." Journal of the European Economic Association 1, 5: $1123-1175$.

Smets, Frank and Raf Wouters. (2007). "Shocks and Frictions in U.S. Business Cycles: A Bayesian DSGE Approach." American Economic Review 97, 3: 506-606.

Shiller, Robert J. (1991). "Comment." In Comparative Performance of U.S. Econometric Models, edited by Lawrence Klein. Oxford, Eng.: Oxford University Press.

Taylor, John, B. (1993a). Macroeconomic Policy in a World Economy. New York: Norton, 1993.

Taylor, John, B. (1993b). "Discretion versus Policy Rules in Practice." Carnegie-Rochester Conference Series on Public Policy, 39: 195-214.

Taylor, John, B. (1999). ed. Monetary Policy Rules. Chicago: University of Chicago Press, 1999.

Taylor, John, B. (1980). "Aggregate Dynamics and Staggered Contracts." Journal of Political Economy 88: 1-24.

Volker Wieland, Tobias Cwik, Gernot Mueller, Sebastian Schmidt and Maik Wolters (2009).

"A New Comparative Approach to Macroeconomic Modelling and Policy Analysis"

Manuscript, Center for Financial Studies, Frankfurt. 
Table 1

Optimized 2-, 3- and 4-Parameter Rules

$$
i_{t}=\rho i_{t-1}+\alpha \pi_{t}+\beta_{0} y_{t}+\beta_{1} y_{t-1}
$$

\begin{tabular}{|c|c|c|c|c|c|c|c|c|}
\hline \multirow[t]{2}{*}{ Model } & \multicolumn{4}{|c|}{$\lambda_{\mathrm{y}}=0$} & \multicolumn{4}{|c|}{$\lambda_{y}=1$} \\
\hline & $\rho$ & $\alpha$ & $\beta_{0}$ & $\beta_{1}$ & $\rho$ & $\alpha$ & $\beta_{0}$ & $\beta_{1}$ \\
\hline $\begin{array}{l}\text { TAYLOR } \\
\text { SW } \\
\text { CEE/ACEL }\end{array}$ & 2 Para & $\begin{array}{l}2.54 \\
2.33 \\
4.45\end{array}$ & $\begin{array}{c}0.19 \\
-0.10 \\
0.28\end{array}$ & & & $\begin{array}{l}3.00 \\
2.04 \\
2.57\end{array}$ & $\begin{array}{l}0.52 \\
0.26 \\
0.45\end{array}$ & \\
\hline $\begin{array}{l}\text { TAYLOR } \\
\text { SW } \\
\text { CEE/ACEL }\end{array}$ & $\begin{array}{c}3 \text { Para } \\
0.98 \\
1.06 \\
0.97\end{array}$ & $\begin{array}{l}\text { ers } \\
0.37 \\
0.49 \\
0.99\end{array}$ & $\begin{array}{l}0.09 \\
0.01 \\
0.02\end{array}$ & & $\begin{array}{l}0.98 \\
1.13 \\
2.84\end{array}$ & $\begin{array}{c}0.21 \\
0.012 \\
7.85\end{array}$ & $\begin{array}{c}0.53 \\
0.015 \\
-2.12\end{array}$ & \\
\hline $\begin{array}{l}\text { TAYLOR } \\
\text { SW } \\
\text { CEE/ACEL }\end{array}$ & $\begin{array}{c}4 \text { Para } \\
0.98 \\
1.06 \\
1.01 \\
\end{array}$ & $\begin{array}{l}\text { ers } \\
0.37 \\
0.46 \\
1.11 \\
\end{array}$ & $\begin{array}{c}0.07 \\
-0.03 \\
0.18 \\
\end{array}$ & $\begin{array}{c}0.02 \\
0.03 \\
-0.18 \\
\end{array}$ & $\begin{array}{l}0.96 \\
1.07 \\
1.04 \\
\end{array}$ & $\begin{array}{l}0.18 \\
0.16 \\
0.51 \\
\end{array}$ & $\begin{array}{l}0.41 \\
1.63 \\
2.24 \\
\end{array}$ & $\begin{array}{r}0.19 \\
-1.62 \\
-2.30 \\
\end{array}$ \\
\hline
\end{tabular}

Note: The loss function includes the variance of inflation and the variance of the first-difference of nominal interest rates with a weight of unity. $\lambda y$ denotes the weight on the variance of the output gap.

Table 2

Increase in Loss when Reducing the Number of Parameters

Percentage Increase (Increase in IIP*)

\begin{tabular}{|l|c|c|c|c|}
\hline \multirow{2}{*}{ Model } & \multicolumn{2}{|c|}{$\boldsymbol{\lambda}_{\mathbf{y}}=\mathbf{0}$} & \multicolumn{2}{c|}{$\boldsymbol{\lambda}_{\mathbf{y}}=\mathbf{1}$} \\
\cline { 2 - 5 } & $\begin{array}{c}\text { 4 versus 3 } \\
\text { Parameters }\end{array}$ & $\begin{array}{c}\text { 3 versus 2 } \\
\text { Parameters }\end{array}$ & $\begin{array}{c}\text { 4 versus 3 } \\
\text { Parameters }\end{array}$ & $\begin{array}{c}\text { 3 versus 2 } \\
\text { Parameters }\end{array}$ \\
\hline TAYLOR & $0.12 \%(0.001)$ & $278 \%(1.38)$ & $1.81 \%(0.07)$ & $98.8 \%(2.14)$ \\
SW & $0.22 \%(0.001)$ & $316 \%(0.78)$ & $10.6 \%(0.47)$ & $25.6 \%(1.17)$ \\
CEE/ACEL & $5.10 \%(0.001)$ & $229 \%(0.04)$ & $14.4 \%(0.11)$ & $9.67 \%(0.11)$ \\
\hline
\end{tabular}

* The values in parentheses measure the increase in absolute loss in terms of the implied inflation (variability) premia proposed by Kuester and Wieland (2008). The IIP corresponds to the increase in the standard deviation of the inflation rate (in percentage point terms) that would imply an equivalent increase in absolute loss. 
Table 3

Robustness of Policy Rules

\begin{tabular}{|c|c|c|c|c|c|c|}
\hline Rule & \multicolumn{2}{|c|}{ TAYLOR-2-Par. Rule } & \multicolumn{2}{|c|}{ TAYLOR-3-Par. Rule } & \multicolumn{2}{|c|}{ TAYLOR-4-Par. Rule } \\
\hline Model & SW & ACEL & SW & ACEL & SW & ACEL \\
\hline $\operatorname{IIP}\left(\lambda_{y}=0\right)$ & 0.37 & 0.03 & 0.83 & 0.12 & 0.90 & 0.14 \\
\hline $\operatorname{IIP}\left(\lambda_{y}=1\right)$ & 0.17 & 0.001 & 5.41 & M.E. & 7.18 & M.E. \\
\hline Rule & \multicolumn{2}{|c|}{ SW-2-Par. Rule } & \multicolumn{2}{|c|}{ SW-3-Par. Rule } & \multicolumn{2}{|c|}{ SW-4-Par. Rule } \\
\hline Model & TAYLOR & ACEL & TAYLOR & ACEL & TAYLOR & ACEL \\
\hline $\operatorname{IIP}\left(\lambda_{\mathrm{y}}=0\right)$ & 0.27 & 0.15 & 0.13 & 0.02 & 0.15 & 0.02 \\
\hline $\operatorname{IIP}\left(\lambda_{y}=1\right)$ & 0.86 & 0.03 & 3.20 & 0.21 & 2.71 & 0.13 \\
\hline Rule & \multicolumn{2}{|c|}{ ACEL-2-Par. Rule } & \multicolumn{2}{|c|}{ ACEL-3-Par. Rule } & \multicolumn{2}{|c|}{ ACEL-4-Par. Rule } \\
\hline Model & SW & TAYLOR & SW & TAYLOR & SW & TAYLOR \\
\hline $\operatorname{IIP}\left(\lambda_{y}=0\right)$ & 0.54 & 0.76 & 0.11 & 0.27 & 0.09 & 0.34 \\
\hline $\operatorname{IIP}\left(\lambda_{y}=1\right)$ & 0.07 & 0.12 & 108 & 24.9 & 0.53 & 3.85 \\
\hline
\end{tabular}

Note: The values in this table concern the increase in absolute loss under a particular rule relative to the comparable simple policy rule optimized in the respective model. The increase is measured in terms of the implied inflation (variability) premia proposed by Kuester and Wieland (2008). The IIP corresponds to the increase in the standard deviation of the inflation rate (in percentage point terms) that would imply an equivalent increase in absolute loss.

M.E. refers to indeterminacy and the existence of multiple self-fufilling equilibria.

Table 4

Robustness of Policy Rules

(SW and TAYLOR Models only)

\begin{tabular}{|l|c|c|c|}
\hline Rule & TAYLOR-2-Par. Rule & TAYLOR-3-Par. Rule & TAYLOR-4-Par. Rule \\
\hline in Model & SW & SW & in SW \\
IIP $\left(\lambda_{y}=0\right)$ & $0.37(1.08)^{*}$ & 0.83 & 0.90 \\
IIP $\left(\lambda_{y}=1\right)$ & $0.17(1.53)^{*}$ & 5.41 & 7.18 \\
\hline Rule & SW-2-Par. Rule & SW-3-Par. Rule & SW-4-Par. Rule \\
\hline in Model & TAYLOR & TAYLOR & TAYLOR \\
IIP $\left(\lambda_{y}=0\right)$ & $0.27(1.58)^{*}$ & 0.13 & 0.15 \\
IIP $\left(\lambda_{y}=1\right)$ & $0.86(2.64)^{*}$ & 3.20 & 2.71 \\
& & & \\
\hline
\end{tabular}

Note: The values in this table concern the increase in absolute loss under a particular rule relative to the comparable simple policy rule optimized in the respective model. The increase is measured in terms of the implied inflation (variability) premia proposed by Kuester and Wieland (2008). The IIP corresponds to the increase in the standard deviation of the inflation rate (in percentage point terms) that would imply an equivalent increase in absolute loss.

* The values in parenthesis refer to the IIP that results from implementing the 2-parameter rule optimized for the TAYLOR (SW) model instead in the SW (TAYLOR) model and comparing it to the optimized 4-parameter rule for that model. 
Table 5

Optimized Model-Averaging Rules (2-, 3- and 4-Parameters)

$$
i_{t}=\rho i_{t-1}+\alpha \pi_{t}+\beta_{0} y_{t}+\beta_{1} y_{t-1}
$$

\begin{tabular}{|l|cccc|}
\hline Equal weights on SW & & & & \\
TAYLOR and ACEL & $\rho$ & $\alpha$ & $\beta_{0}$ & $\beta_{1}$ \\
\hline & & & & \\
2-parameter rule & & 2.75 & 0.52 & \\
3-parameter rule & 1.05 & 0.41 & 0.23 & \\
4-parameter rule & 1.06 & 0.19 & 0.67 & -0.59 \\
\hline
\end{tabular}

Note: The loss function includes the variance of inflation, the variance of the output gap and the variance of the first-difference of nominal interest rates with a weight of unity

Table 6

Robustness of Model-Averaging Policy Rules (IIP's)

\begin{tabular}{|l|c|c|c|}
\hline Model & 2-Par. Rule & 3-Par. Rule & 4-Par. Rule \\
\hline & & & \\
SW & $0.11(1.50)^{*}$ & 1.02 & 0.47 \\
TAYLOR & $0.03(0.17)^{*}$ & 0.56 & 1.28 \\
ACEL & $0.00(2.18)^{*}$ & 0.27 & 0.12 \\
\hline
\end{tabular}

Note: The values in this table concern the increase in absolute loss under a particular rule relative to the comparable simple policy rule optimized in the respective model. The increase is measured in terms of the implied inflation (variability) premia proposed by Kuester and Wieland (2008). The IIP corresponds to the increase in the standard deviation of the inflation rate (in percentage point terms) that would imply an equivalent increase in absolute loss.

* The values in parenthesis refer to the IIP that results from implementing the 2-parameter rule optimized for the TAYLOR (SW) model instead in the SW (TAYLOR) model and comparing it to the optimized 4-parameter rule for that model. 
Figure 1

The Effect of a Policy Shock on Interest Rates, Output and Inflation 1 Percentage Point Increase in the Nominal Policy Rate
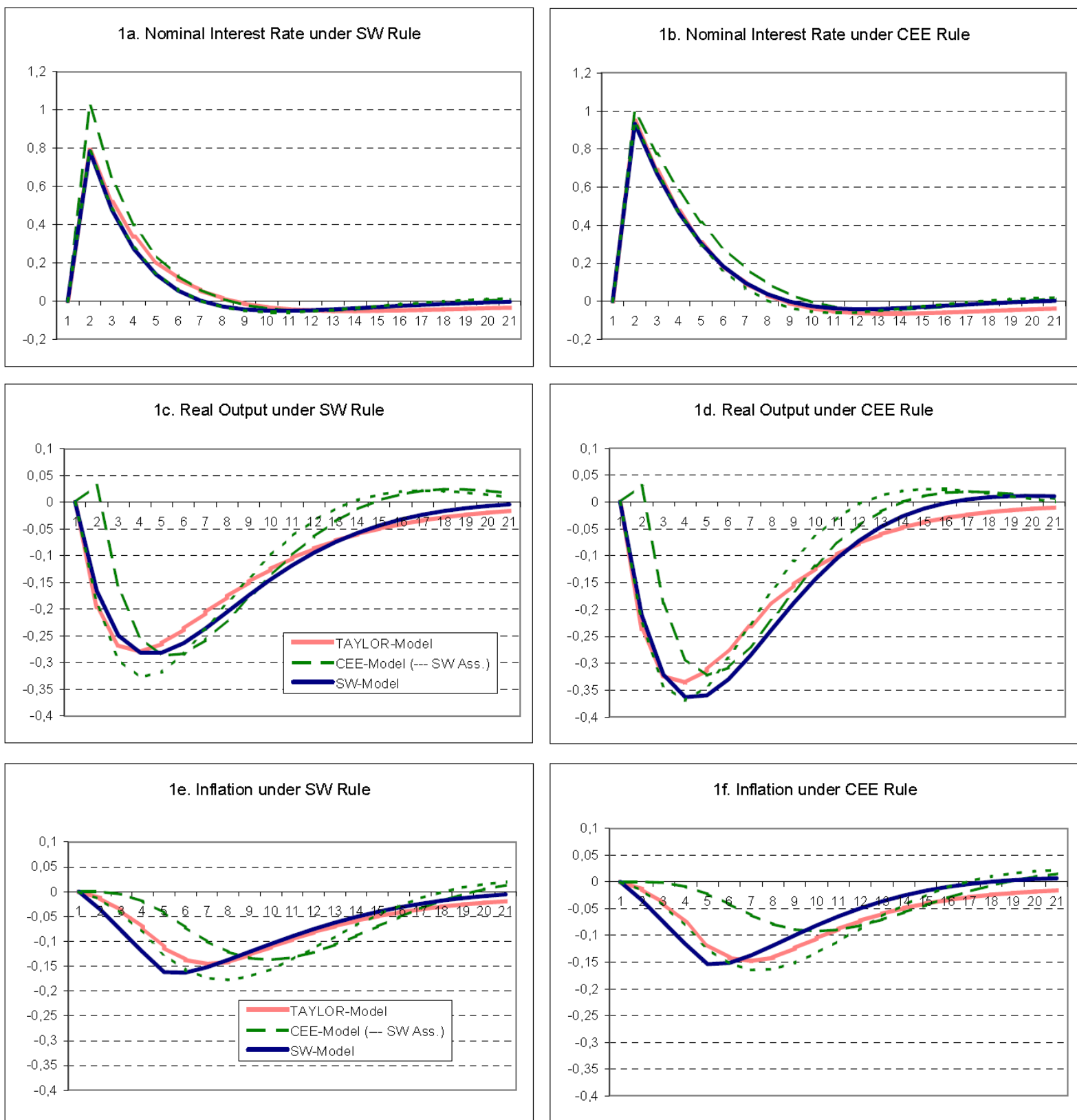
Figure 2

Common Aspects of the Transmission Mechanism in the Three Models (SW Rule)
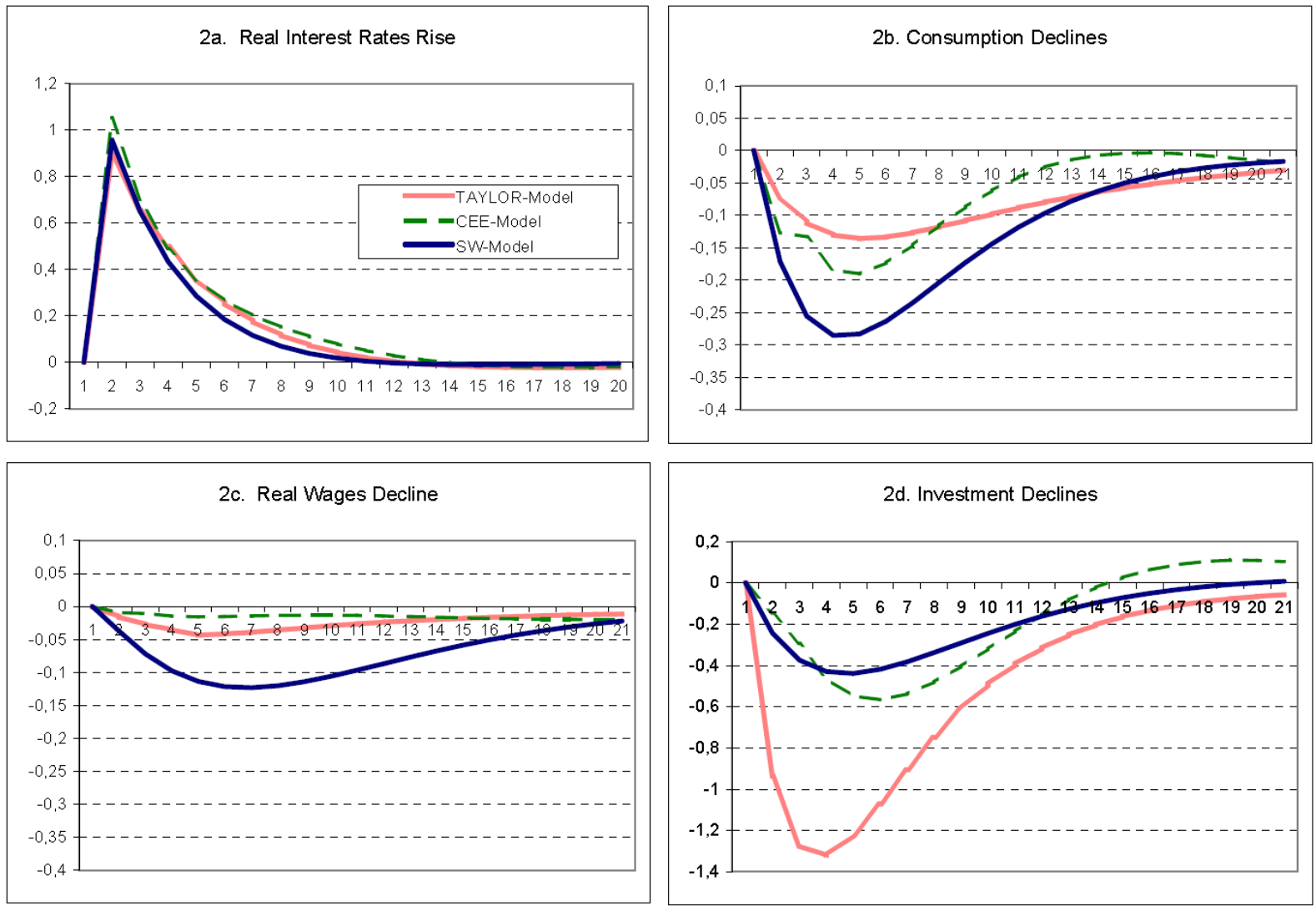
Figure 3

Differences in the Transmission Mechanism in the Three Models (SW Rule)

Only the TAYLOR Model Accounts for International Feedback

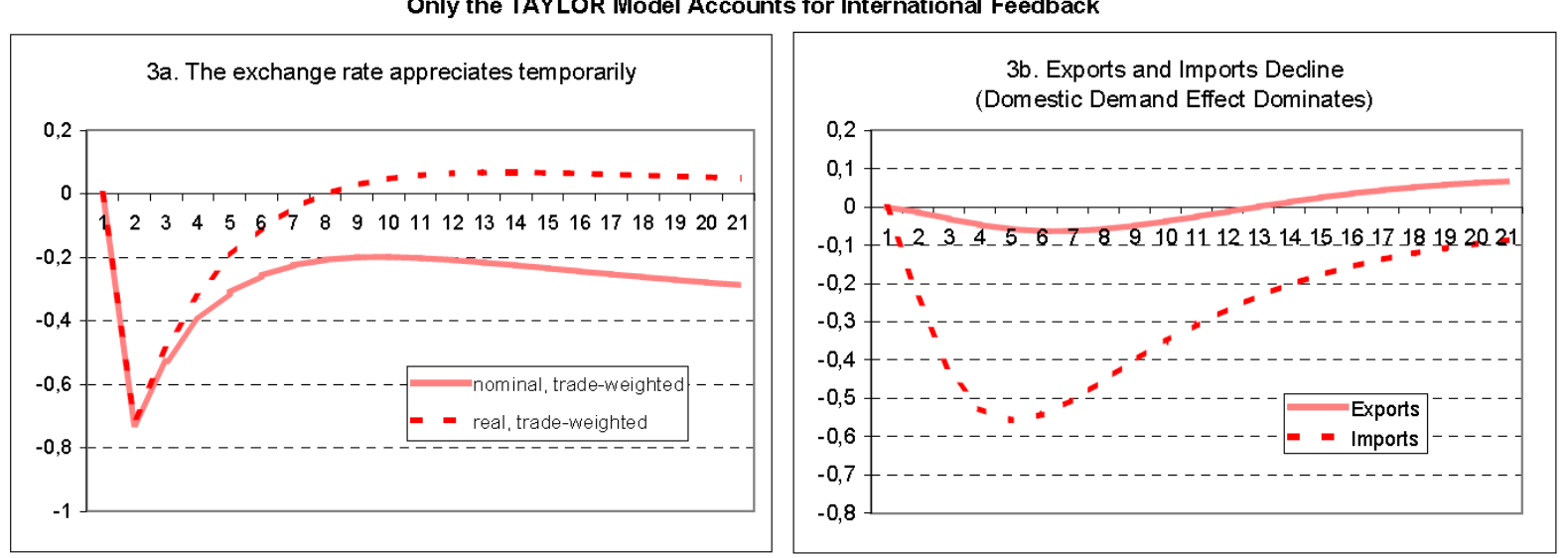

Only the SW and CEE Models Account for Labor Supply, Capital Stock and Capital Utilization
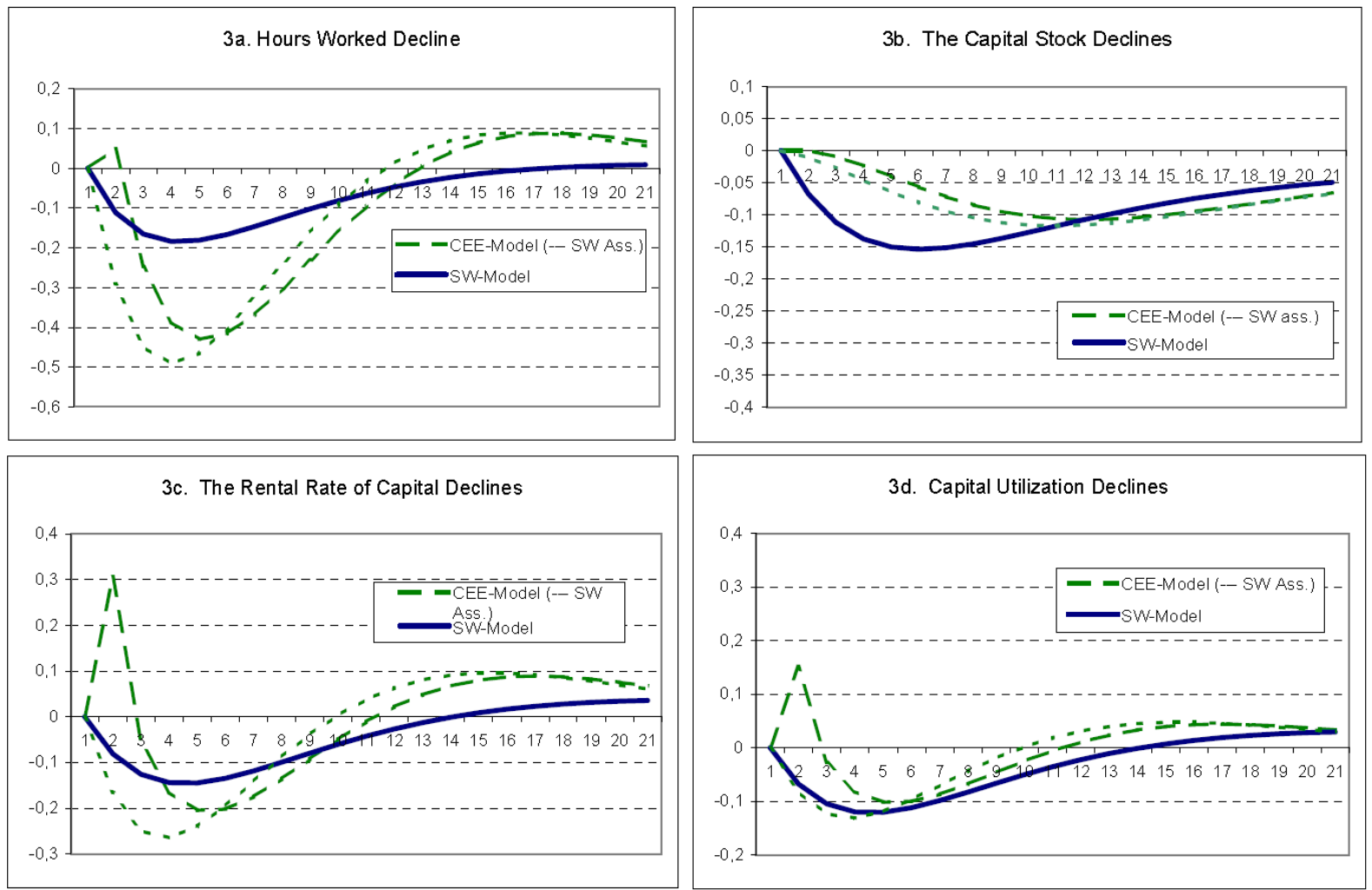
Figure 4

Term Premium Shock in the Taylor and SW Models (SW Rule)

1 Percentage Point Increase in the Term Premium
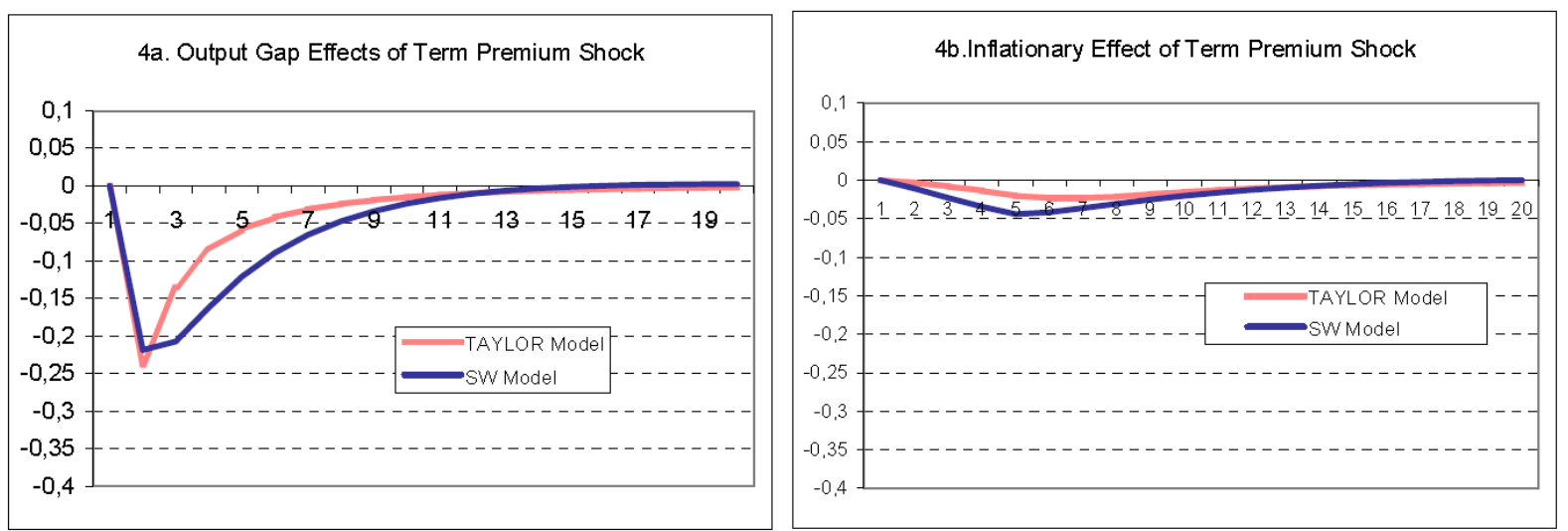


\section{Figure 5}

"Demand" Shocks in the Taylor, SW and CEE Models (SW Rule)

1 Percentage Increase in the Relevant Variables
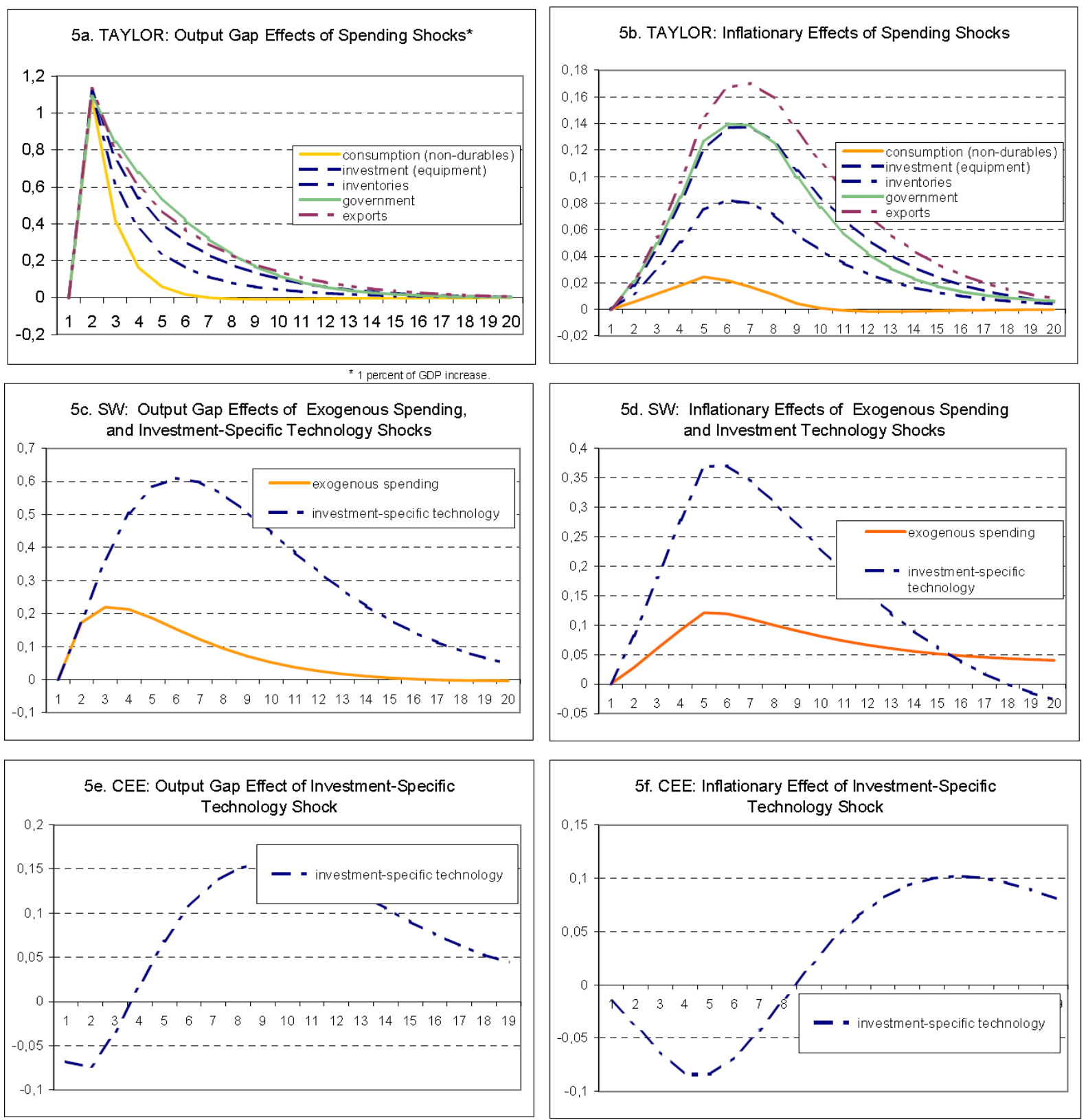


\section{Figure 6}

Short-Run and Long-Run "Supply" Shocks in Taylor, SW and CEE Models (SW Rule) 1 Percentage Increase in the Relevant Variables
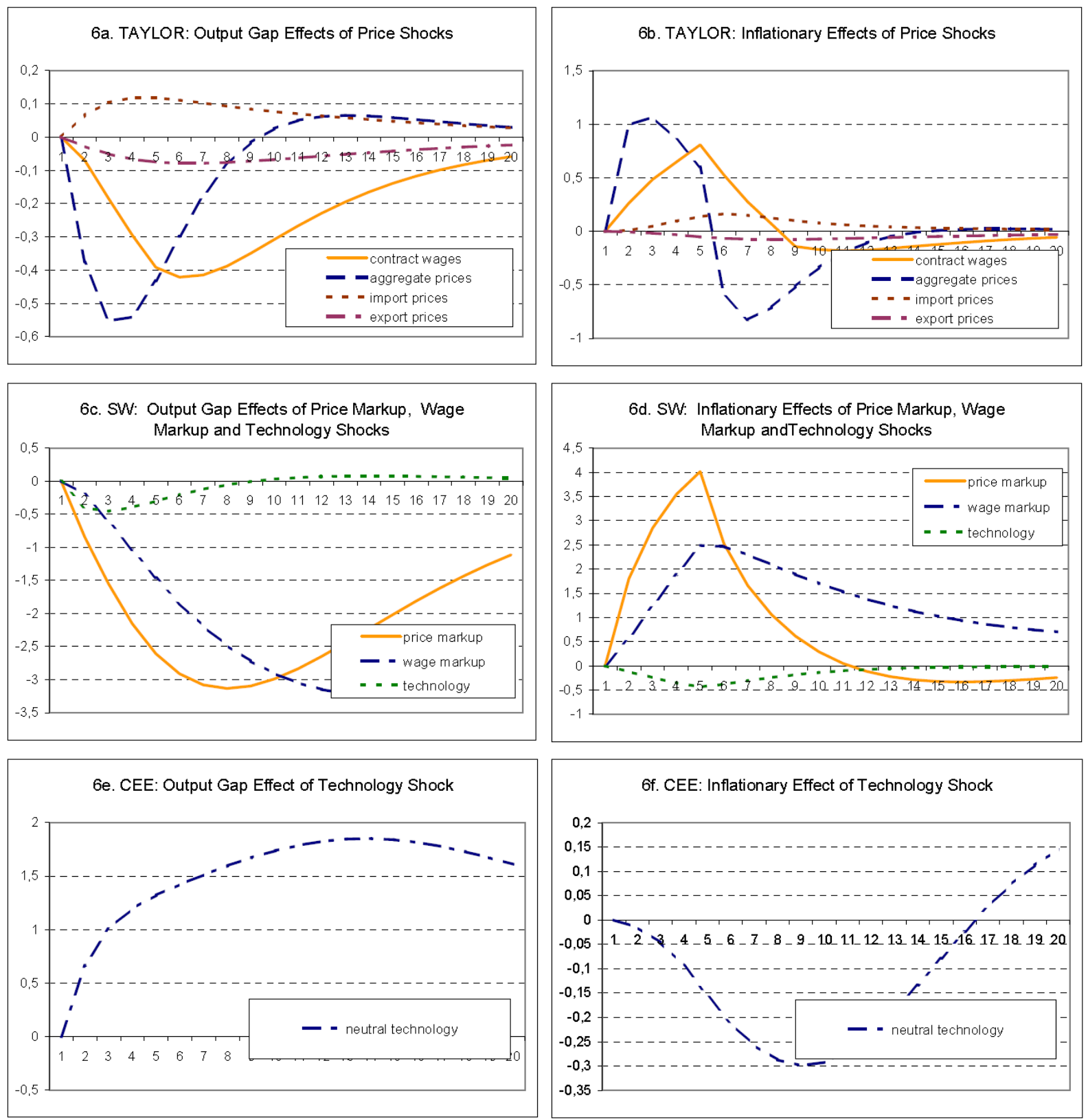


\section{Appendices}

A 1: Models Included in or Submitted to the Model Base as of March $2009^{15}$

\section{Small Calibrated Models}

1.1 Woodford, Rotemberg (1997)

NK_RW97

1.2 Levin Wieland Williams (2003)

NK_LWW03

1.3 Clarida Gali Gertler (1999)

1.4 Clarida Gali Gertler 2-Country (2002)

NK_CGG99

1.5. Ravenna-Walsh (2003)

2C_CGG02

NK_RW03

1.6. McCallum, Nelson (1999)

NK_MCN99

\section{Estimated US Models}

2.1 Fuhrer \& Moore (1995)

2.2 FRB Monetary Studies, Orphanides, Wieland (1998)

2.3 FRB-US model linearized by Levin, Wieland, Williams (2003)

2.4 FRB-US model 08 linearized by Laubach (2008)

2.5 FRB-US model 08 mixed expectations, linearized by Laubach (2008)

2.6 Smets Wouters (2007)

2.7 CEE/ACEL Altig, Christiano, Eichenbaum, Linde (2004)

$(\mathrm{m}=$ monetary policy shock, $\mathrm{t}=$ technology shock, $\mathrm{sw}=\mathrm{SW}$ assumptions $=$ no cost channel, no timing constraints)

2.8. New Fed US Model by Edge Kiley Laforte (2007)

\section{Estimated Euro Area Models}

3.1 Coenen Wieland (2005) (ta: Taylor-staggered contracts)

3.2 Coenen Wieland (2005) (fm: Fuhrer-Moore staggered contracts)

3.3 ECB Area Wide model linearized by Kuester \& Wieland (2005)

3.4 Smets and Wouters (2003)

3.5. Euro Area Model of Sveriges Riksbank (Adolfson et al. 2008a)

3.6. QUEST III: Euro Area Model of the DG-ECFIN EU

3.7. ECB New-Area Wide Model of Coenen, McAdam, Straub (2008)

\section{Estimated Small Open-Economy Models (other countries)}

\subsection{RAMSES Model of Sveriges Riskbank, Adolfson et al.(2008b)}

\section{Estimated/Calibrated Multi-Country Models}

5.1 Taylor (1993) G7 countries

5.2 Coenen and Wieland (2002, 2003) G3 countries

5.3 IMF model of euro area \& CZrep, Laxton \& Pesenti (2003)

5.4 FRB-SIGMA Erceg Gust Guerrieri (2008)
US FM95

US MSR98

US FRB03

US_FRB08

US_FRB08mx

US SW07

US ACELm

US ACELt

US ACELswm

US ACELswt

US_NFED08
SE RAMSES08

EA_CW05ta

EA_CW05fm

EA_AWM05

EA SW03

EA_SR08

EA_QUEST3

EA_NAWM08

G7_TAY93

G3 CW03

USCZ GEM03
G2_SIGMA08

\footnotetext{
${ }^{15}$ See Wieland, Cwik, Müller, Schmidt and Wolters (2009) for a detailed exposition of the platform for model comparison.
} 


\section{A 2: Additional Tables}

The following tables provide information on a sensitivity study with a smaller weight of 05 on the standard deviation of changes in the short-term nominal interest rate. Further sensitivity studies (not shown) were conducted with respect to a weight of 0.5 on the output gap, with respect to the definition of the output gap relative to steady-state output rather than flexibleprice output (SW and CEE/ACEL model), and with respect to a version of the CEE/ACEL model with the SW assumptions of no cost-channel and no exogenous delay of the impact of policy.

Table A2-1

Optimized 2-, 3- and 4-Parameter Rules

$$
i_{t}=\rho i_{t-1}+\alpha \pi_{t}+\beta_{0} y_{t}+\beta_{1} y_{t-1}
$$

\begin{tabular}{|c|c|c|c|c|c|c|c|c|}
\hline \multirow[t]{2}{*}{ Model } & \multicolumn{4}{|c|}{$\lambda_{y}=0$} & \multicolumn{4}{|c|}{$\lambda_{y}=1$} \\
\hline & $\rho$ & $\alpha$ & $\beta_{0}$ & $\beta_{1}$ & $\rho$ & $\alpha$ & $\beta_{0}$ & $\beta_{1}$ \\
\hline $\begin{array}{l}\text { TAYLOR } \\
\text { SW } \\
\text { CEE/ACEL }\end{array}$ & 2 Para & $\begin{array}{l}\text { rs } \\
3.00 \\
2.81 \\
5.91\end{array}$ & $\begin{array}{c}0.22 \\
-0.12 \\
0.27\end{array}$ & & & $\begin{array}{l}3.46 \\
2.15 \\
2.87\end{array}$ & $\begin{array}{l}0.78 \\
0.30 \\
0.49\end{array}$ & \\
\hline $\begin{array}{l}\text { TAYLOR } \\
\text { SW } \\
\text { CEE/ACEL }\end{array}$ & $\begin{array}{c}3 \text { Para1 } \\
0.97 \\
1.05 \\
0.97\end{array}$ & $\begin{array}{l}\text { rs } \\
1.44 \\
0.71 \\
0.99\end{array}$ & $\begin{array}{l}0.02 \\
0.01 \\
0.02\end{array}$ & & $\begin{array}{l}0.97 \\
1.12 \\
2.14 \\
(0.01)^{*}\end{array}$ & $\begin{array}{c}0.27 \\
0.012 \\
8.29 \\
(2.90)^{*} \\
\end{array}$ & $\begin{array}{c}0.76 \\
0.015 \\
-1.99 \\
(0.50)^{*} \\
\end{array}$ & \\
\hline $\begin{array}{l}\text { TAYLOR } \\
\text { SW } \\
\text { CEE/ACEL }\end{array}$ & $\begin{array}{c}4 \text { Para1 } \\
0.98 \\
1.05 \\
1.01 \\
\end{array}$ & $\begin{array}{l}\text { rs } \\
0.51 \\
0.65 \\
1.86 \\
\end{array}$ & $\begin{array}{c}0.09 \\
-0.04 \\
0.15 \\
\end{array}$ & $\begin{array}{r}0.02 \\
0.05 \\
-0.15 \\
\end{array}$ & $\begin{array}{l}0.95 \\
1.07 \\
1.01 \\
\end{array}$ & $\begin{array}{l}0.24 \\
0.21 \\
0.75 \\
\end{array}$ & $\begin{array}{l}0.60 \\
2.22 \\
3.11 \\
\end{array}$ & $\begin{array}{r}0.26 \\
-2.21 \\
-3.18 \\
\end{array}$ \\
\hline
\end{tabular}

Note: The loss function includes the variance of inflation and the variance of the first-difference of nominal interest rates with a weight of unity. $\lambda y$ denotes the weight on the variance of the output gap.

${ }^{*}$ The ACEL model, which is has only two shocks, exhibits only very small values of the loss function and multiple local optima. For example, a local optimum with much smaller parameter values is displayed in parenthesis in smaller font.

Table A2-2

Increase in Loss when Reducing the Number of Parameters

Percentage Increase (Increase in IIP*)

\begin{tabular}{l|c|c|c|c|} 
& \multicolumn{2}{c}{$\boldsymbol{\lambda}_{\mathbf{y}}=\mathbf{0}$} & \multicolumn{2}{c}{$\boldsymbol{\lambda}_{\mathbf{y}}=\mathbf{1}$} \\
Model & 4 versus 3 & 3 versus 2 & 4 versus 3 & 3 versus 2 \\
\hline TAYLOR & $0.10 \%(0.001)$ & $210 \%(1.04)$ & $1.78 \%(0.06)$ & $88.0 \%(1.81)$ \\
SW & $0.26 \%(0.001)$ & $253 \%(0.62)$ & $12.4 \%(0.53)$ & $23.7 \%(1.10)$ \\
CEE/ACEL & $3.51 \%(0.001)$ & $217 \%(0.03)$ & $13.7 \%(0.10)$ & $11.18 \%(0.12)$ \\
\hline
\end{tabular}

* The values in parentheses measure the increase in absolute loss in terms of the implied inflation (variability) premia proposed by Kuester and Wieland (2008). The IIP corresponds to the increase in the standard deviation of the inflation rate (in percentage point terms) that would imply an equivalent increase in absolute loss. 
Table A2-3

Robustness of Policy Rules

\begin{tabular}{|c|c|c|c|c|c|c|}
\hline Rule & \multicolumn{2}{|c|}{ TAYLOR-2-Par. Rule } & \multicolumn{2}{|c|}{ TAYLOR-3-Par. Rule } & \multicolumn{2}{|c|}{ TAYLOR-4-Par. Rule } \\
\hline Model & SW & ACEL & SW & ACEL & SW & ACEL \\
\hline $\operatorname{IIP}\left(\lambda_{y}=0\right)$ & 0.34 & 0.02 & 0.70 & 0.11 & 0.77 & 0.12 \\
\hline $\operatorname{IIP}\left(\lambda_{y}=1\right)$ & 0.18 & 0.02 & 6.04 & M.E. & 7.63 & M.E. \\
\hline Rule & \multicolumn{2}{|c|}{ SW-2-Par. Rule } & \multicolumn{2}{|c|}{ SW-3-Par. Rule } & \multicolumn{2}{|c|}{ SW-4-Par. Rule } \\
\hline Model & TAYLOR & ACEL & TAYLOR & ACEL & TAYLOR & ACEL \\
\hline $\operatorname{IIP}\left(\lambda_{y}=0\right)$ & 0.19 & 0.11 & 0.12 & 0.01 & 0.13 & 0.02 \\
\hline $\operatorname{IIP}\left(\lambda_{y}=1\right)$ & 1.09 & 0.02 & 3.36 & 0.23 & 2.39 & 0.13 \\
\hline Rule & \multicolumn{2}{|c|}{ ACEL-2-Par. Rule } & \multicolumn{2}{|c|}{ ACEL-3-Par. Rule } & \multicolumn{2}{|c|}{ ACEL-4-Par. Rule } \\
\hline Model & SW & TAYLOR & SW & TAYLOR & SW & TAYLOR \\
\hline $\operatorname{IIP}\left(\lambda_{y}=0\right)$ & 0.47 & 0.82 & 0.10 & 0.28 & 0.12 & 0.46 \\
\hline $\operatorname{IIP}\left(\lambda_{\mathrm{y}}=1\right)$ & 0.08 & 0.27 & 55.4 & 24.4 & 0.54 & 3.57 \\
\hline
\end{tabular}

* The values in this table concern the increase in absolute loss under a particular rule relative to the comparable simple policy rule optimized in the respective model. The increase is measured in terms of the implied inflation (variability) premia proposed by Kuester and Wieland (2008). The IIP corresponds to the increase in the standard deviation of the inflation rate (in percentage point terms) that would imply an equivalent increase in absolute loss. 


\section{A 3: Figures}

Figure A3-1

Common Aspects of the Transmission Mechanism in the Three Models (CEE Rule)
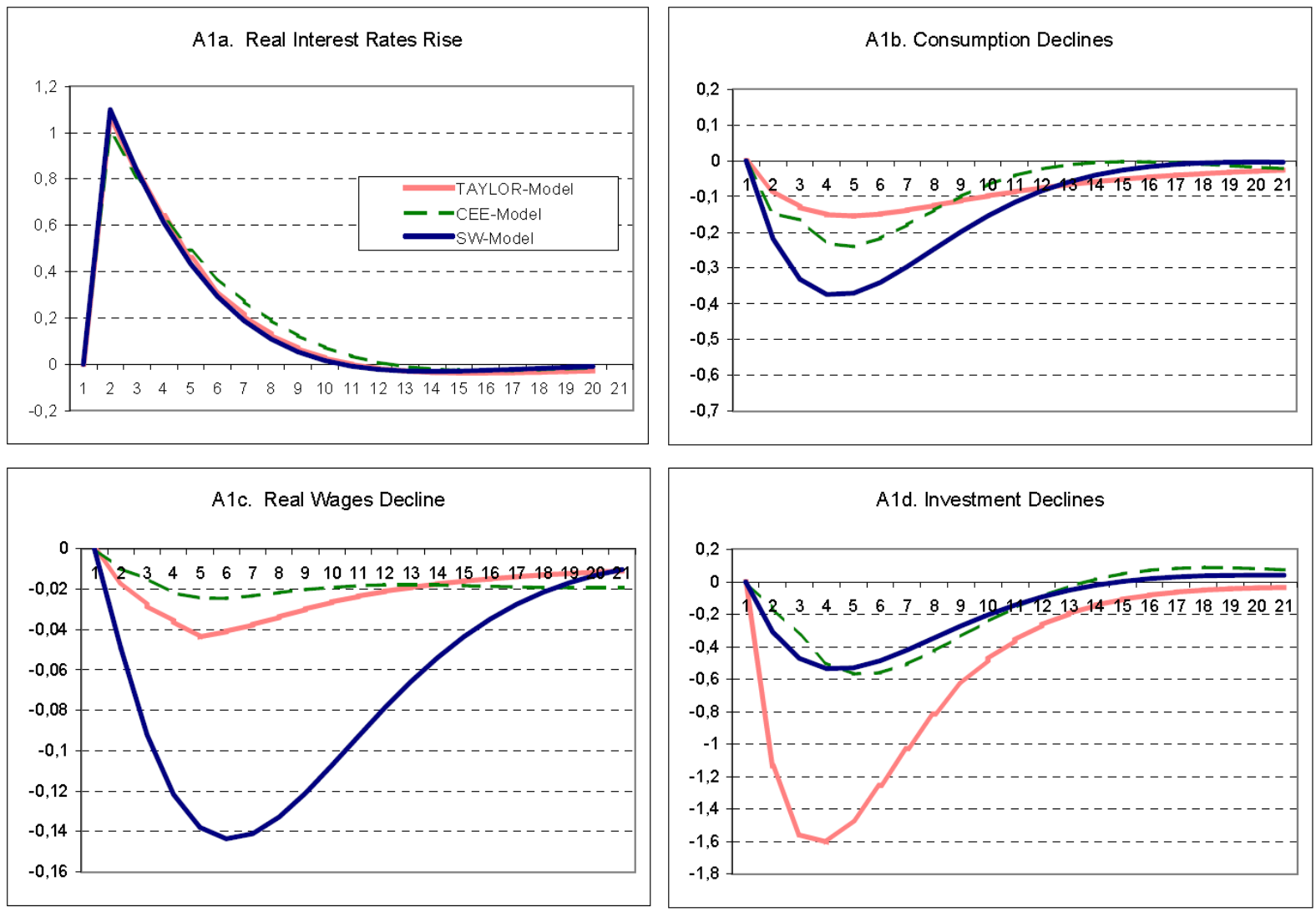
Figure A3-2

Only the TAYLOR Model Accounts for International Feedback (CEE Rule)
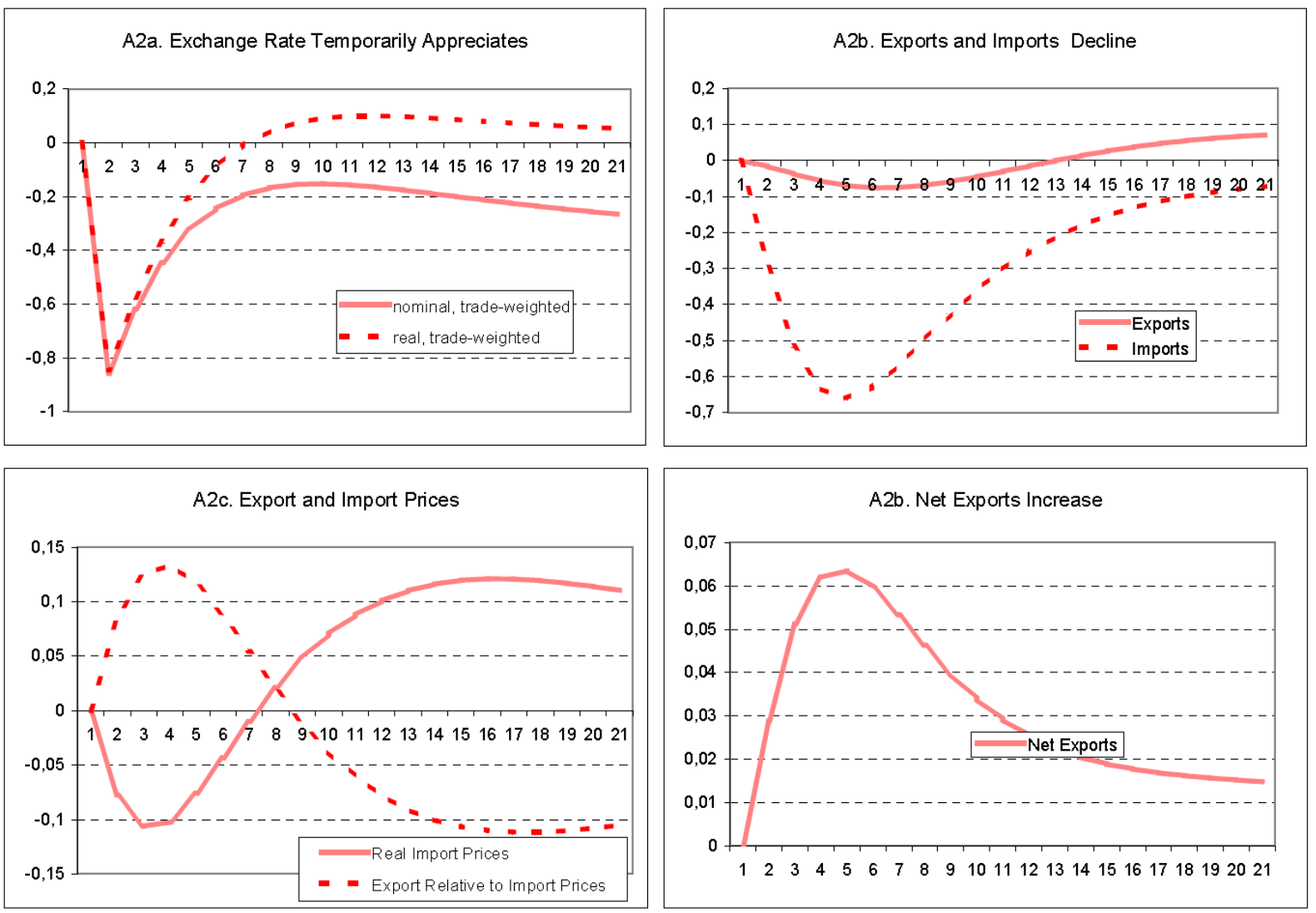
Figure A3-3

Only SW and CEE Account for Labor Supply, Capital Stock and Utilization (CEE Rule)
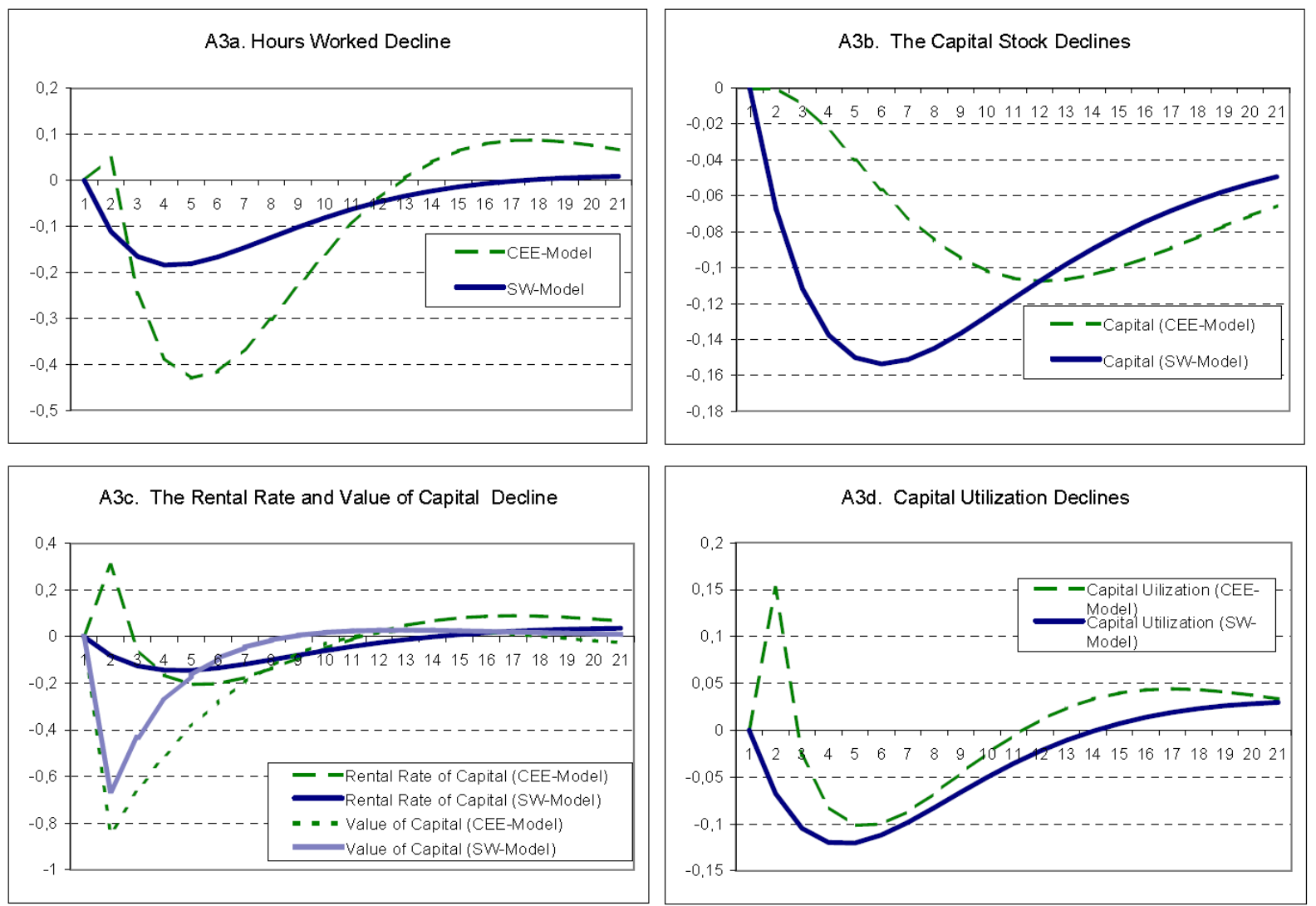